\title{
ON A CLASS OF BOUNDARY CONTROL PROBLEMS
}

\author{
RAiner PicArd, Sascha TrostorfF And Marcus WaUrick
}

\begin{abstract}
We discuss a class of linear control problems in a Hilbert space setting, which covers diverse systems such as hyperbolic and parabolic equations with boundary control and boundary observation even including memory terms. We introduce abstract boundary data spaces in which the control and observation equations can be formulated without strong geometric constraints on the underlying domain. The results are applied to a boundary control problem for the equations of visco-elasticity.
\end{abstract}

Mathematics subject classification (2010): 93C05 (Linear systems), 93C20 (Systems governed by partial differential equations), 93C25 (Systems in abstract spaces).

Keywords and phrases: Linear control systems, well-posedness, evolutionary equations, memory.

\section{REFERENCES}

[1] P. G. CiARLeT AND P. JUn. CiARLet, Another approach to linearized elasticity and a new proof of Korn's inequality, Math. Models Methods Appl. Sci., 15 (2): 259-271, 2005.

[2] R. F. CURTAIn AND G. Weiss, Well posedness of triples of operators (in the sense of linear systems theory), Control and estimation of distributed parameter systems, 4th Int. Conf., Vorau/Austria 1988, ISNM 91, 41-59, 1989.

[3] K.-J. ENGEL, On the characterization of admissible control- and observation operators, Syst. Control Lett., 34 (4): 225-227, 1998.

[4] B. JACOB AND J. R. PARTINGTON, Admissibility of control and observation operators for semigroups: a survey, Ball, Joseph A. (ed.) et al., Current trends in operator theory and its applications. Proceedings of the international workshop on operator theory and its applications (IWOTA), Virginia Tech, Blacksburg, VA, USA, August 6-9, 2002. Basel: Birkhäuser. Operator Theory: Advances and Applications 149, 199-221, 2004.

[5] B. JaCOB AND H. J. ZWART, Linear Port-Hamiltonian systems on infinite-dimensional spaces, Operator Theory: Advances and Applications 223. Basel: Birkhäuser. xii, 217 p., 2012.

[6] A. Kalauch, R. Picard, S. Siegmund, S. Trostorff, and M. Waurick, A Hilbert Space Perspective on Ordinary Differential Equations with Memory Term, J. Dynam. Differential Equations, to appear.

[7] I. LASiecka And R. TRIggiani, Control theory for partial differential equations: continuous and approximation theories. 1: Abstract parabolic systems, Encyclopedia of Mathematics and Its Applications 74. Cambridge: Cambridge University Press. xxi, 644 p., 2000.

[8] I. LASIECKA AND R. TRIgGiani, Control theory for partial differential equations: continuous and approximation theories. 2: Abstract hyperbolic-like systems over a finite time horizon, Encyclopedia of Mathematics and Its Applications. 75. Cambridge: Cambridge University Press. xxi, p. 645-1067, 2000.

[9] R. PICARD, A structural observation for linear material laws in classical mathematical physics, Math. Methods Appl. Sci., 32 (14): 1768-1803, 2009.

[10] R. Picard, S. TrostorfF, And M. Waurick, On Evolutionary Equations with Material Laws Containing Fractional Integrals. (2013) Submitted, http://arxiv.org/abs/1304.7620.

[11] R. Picard And D. McGhee, Partial differential equations. A unified Hilbert space approach, de Gruyter Expositions in Mathematics 55. Berlin: de Gruyter. xviii, 2011. 
[12] R. PiCARD, S. TROSTORFF, AND M. WAURICK, A note on a class of conservative, well-posed linear control systems. Progress in Partial Differential Equations: Asymptotic Profiles, Regularity and WellPosedness (M. Reissig, M. Ruzhansky eds.), Springer Proceedings in Mathematics \& Statistics, Vol. 44, 261-286, Springer (2013).

[13] R. PiCARD, S. TROSTORFF, AND M. WAURICK, On a comprehensive Class of Linear Control Problems, Technical report, TU Dresden, 2012. Submitted. arXiv:1208.3140.

[14] D. SAlAmon, Infinite dimensional linear systems with unbounded control and observation: A functional analytic approach, Trans. Am. Math. Soc., 300: 383-431, 1987.

[15] D. Salamon, Realization theory in Hilbert space, Math. Syst. Theory, 21 (3): 147-164, 1989.

[16] S. TrostorfF, An alternative approach to well-posedness of a class of differential inclusions in Hilbert spaces, Nonlinear Anal., Theory Methods Appl., Ser. A, Theory Methods, 75 (15): 5851$5865,2012$.

[17] S. TrostorfF, On Integro-Differential Inclusions with Operator-valued Kernels, Math. Methods Appl. Sci., to appear.

[18] S. TrostorfF, Autonomous Evolutionary Inclusions with Applications to Problems with Nonlinear Boundary Conditions, Int. J. Pure Appl. Math., 85, 2 (2013), 303-338.

[19] M. WAURICK, Homogenization in fractional elasticity, SIAM Journal on Mathematical Analysis, to appear. arXiv:1302.1731.

[20] N. WECK, Local compactness for linear elasticity in irregular domains, Math. Methods Appl. Sci., 17 (2): 107-113, 1994.

[21] G. WeISS, Admissibility of unbounded control operators, SIAM J. Control Optimization, 27 (3): $527-$ $545,1989$.

[22] G. WEISs, The representation of regular linear systems on Hilbert spaces, Control and estimation of distributed parameter systems, 4th Int. Conf., Vorau/Austria 1988, ISNM 91, 401-416, 1989.

[23] G. WEISS, Transfer functions of regular linear systems. I: Characterizations of regularity, Trans. Am. Math. Soc., 342 (2): 827-854, 1994.

[24] G. WeISS AND M. TUCSNAK, How to get a conservative well-posed linear system out of thin air. Part I. Well-posedness and energy balance, ESAIM: Control, Optimisation and Calculus of Variations, 9: 247-273, 2003. 